\title{
Characterization of a megapixel CMOS charge dump and read camera
}

J. R. Kimbrough, P. M. Bell, P. S. Datte, M. S.

Thao, E. O. Vergel de Dios, A. S. Peters

August 28, 2013

SPIE Conference

San Diego, CA, United States

August 25, 2013 through August 29, 2013 
This document was prepared as an account of work sponsored by an agency of the United States government. Neither the United States government nor Lawrence Livermore National Security, LLC, nor any of their employees makes any warranty, expressed or implied, or assumes any legal liability or responsibility for the accuracy, completeness, or usefulness of any information, apparatus, product, or process disclosed, or represents that its use would not infringe privately owned rights. Reference herein to any specific commercial product, process, or service by trade name, trademark, manufacturer, or otherwise does not necessarily constitute or imply its endorsement, recommendation, or favoring by the United States government or Lawrence Livermore National Security, LLC. The views and opinions of authors expressed herein do not necessarily state or reflect those of the United States government or Lawrence Livermore National Security, LLC, and shall not be used for advertising or product endorsement purposes. 


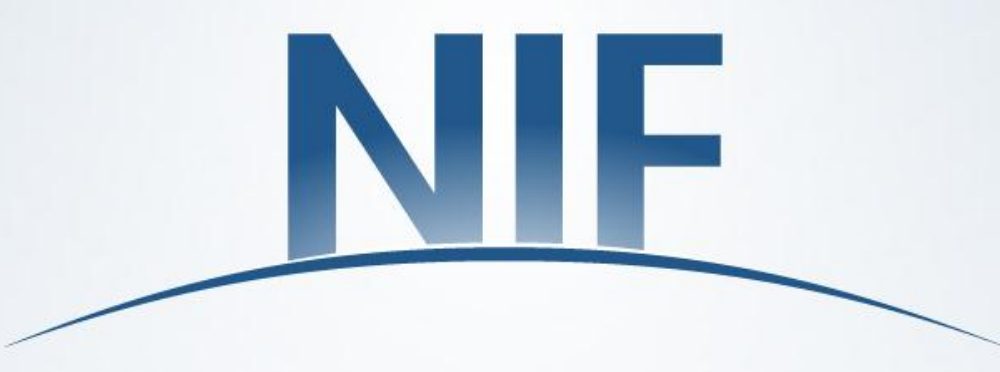

\section{Characterization of a megapixel CMOS charge dump and read camera}

\section{Presentation to SPIE Conference}

August 27, 2013

J. R. Kimbrougha, P. M. Bella, P. S. Dattea, M. S. Thao ${ }^{a}$

E. O. Vergel de Dios ${ }^{a}$, A. .S. Peters ${ }^{b}$

aLawrence Livermore National Laboratory

bSpectral Instruments, Inc. 
Problem: At high neutron yields the radiation-induced noise in electronic cameras overwhelms star removal software

Simulated noise added to image
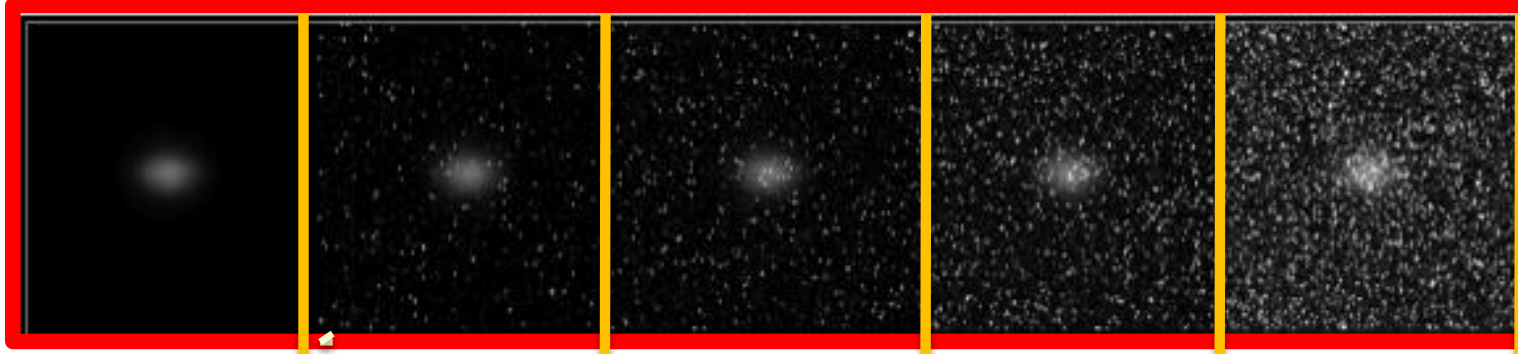

Noise reduction software applied
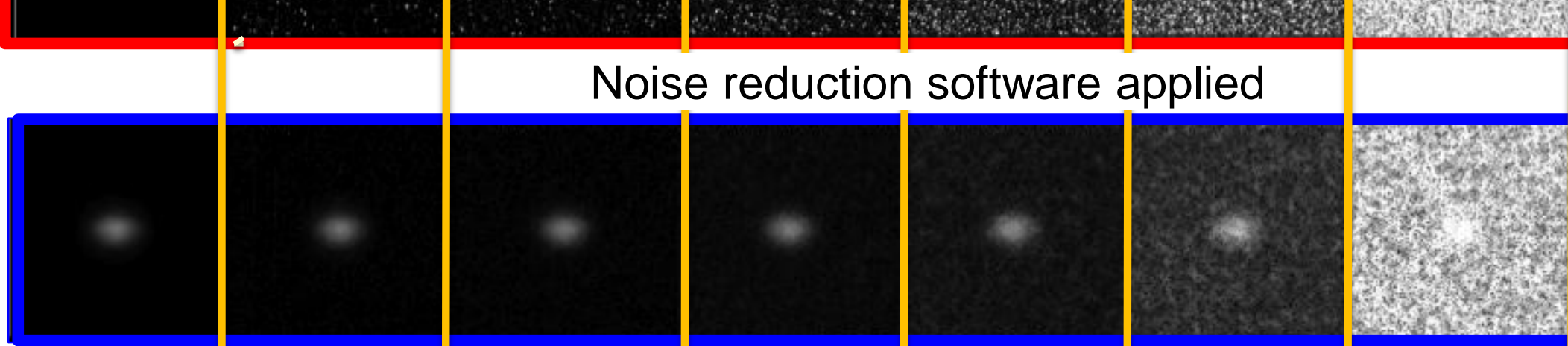

Line out through CCD

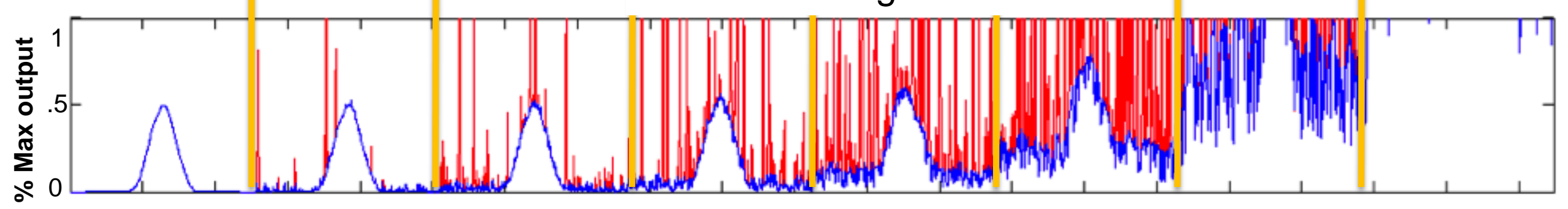

\begin{tabular}{|c|c|c|c|c|c|c|}
\hline Yn @ TCC 0 & $3 \times 10^{12}$ & $6 \times 10^{12}$ & $1.5 \times 10^{13}$ & $3 \times 10^{13}$ & $6 \times 10^{13}$ & $1.5 \times 10^{14}$ \\
\hline$\Phi\left(\mathrm{n} . / \mathrm{cm}^{2}\right) 0$ & $1 \times 10^{7}$ & $2 \times 10^{7}$ & $5 \times 10^{7}$ & $1 \times 10^{8}$ & $2 \times 10^{8}$ & $5 \times 10^{8}$ \\
\hline
\end{tabular}

At high yields the data-containing image cannot be recovered 


\section{Solution: Dump and Read with a radiation hardened}

camera

- During the prompt radiation pulse of neutrons and downscattered gamma rays ...

- Store the image on a long persistence phosphor

- Dump the charge generated in the pixels

- The sensor is approximately $160 x$ more sensitive to radiation than the fiber optic and phosphor

- Once the prompt radiation has passed, start the exposure and the residual image on the phosphor is recorded.

- Despite imaging the lower intensity of the decaying phosphor, the signal to noise ratio increases since unwanted pixel charge was dumped 


\section{Concept: Dumping occurs over microseconds while image exposure occurs over milliseconds}

- Radiation induced charge in the image sensor is due to interaction in Si of $14 \mathrm{MeV}$ neutrons and down-scattered gamma radiation

- Pixel charge is dumped during the prompt radiation pulse

- Image captured on P20 phosphor with long decay time

- Wait until the prompt radiation has passed and then start the exposure.

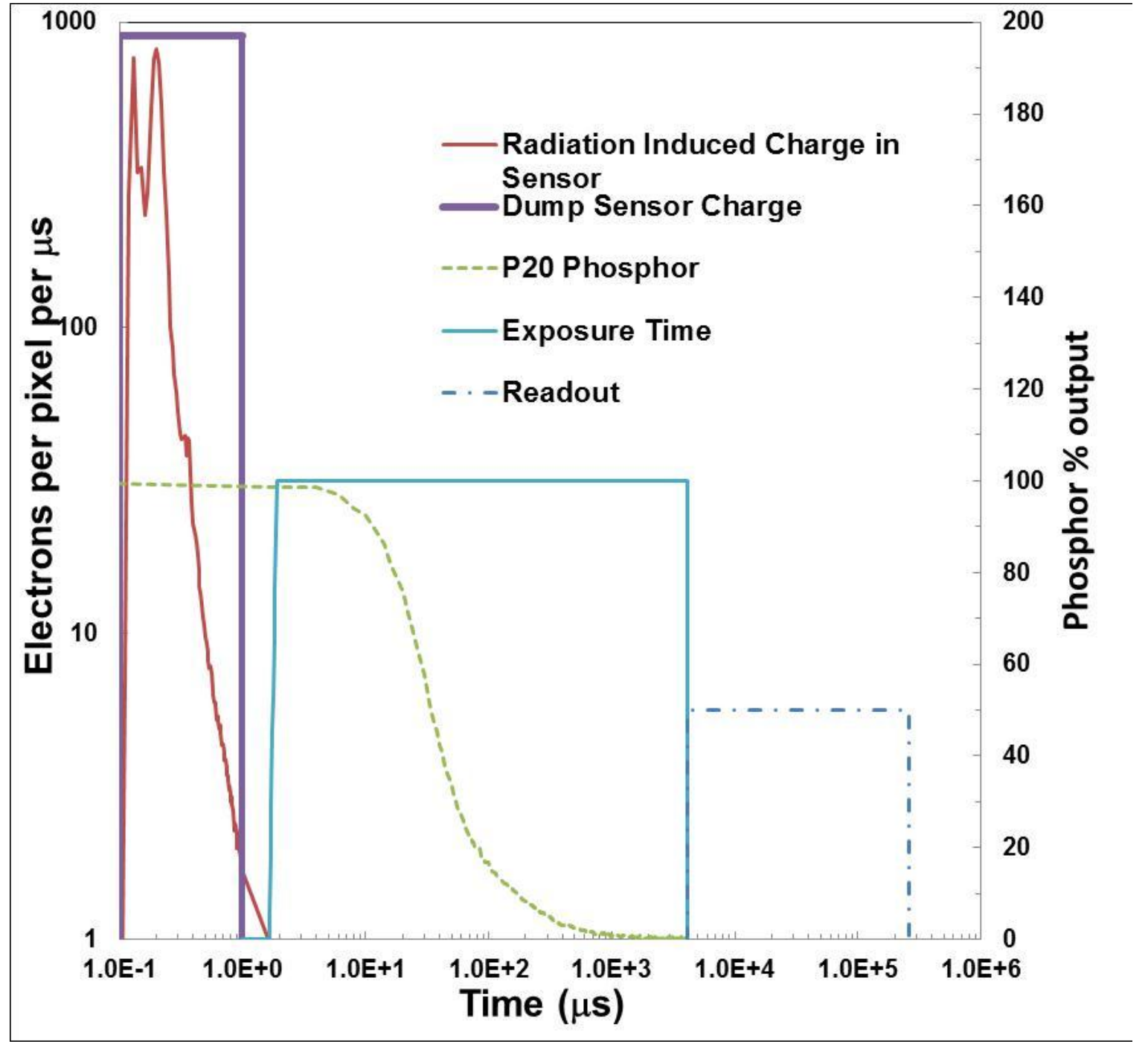


Developed a prototype radiation tolerant camera based on CMOS Active Pixel Device (APD) to test the dump and read concept

- Camera design constraints:

- Match the size of SI1000 CCD cameras used in National Ignition Facility (NIF) X-ray diagnostics

- Compatible with existing NIF software

- Both optical and electrical trigger inputs

- At least a $2 \mathrm{k}$ by $2 \mathrm{k}$ CMOS imager

- Global reset capability

- All parts excluding the imager operate up to $10 \mathrm{krad}(\mathrm{Si})$

- Prototype is the Model 1050 developed with Spectral Instruments

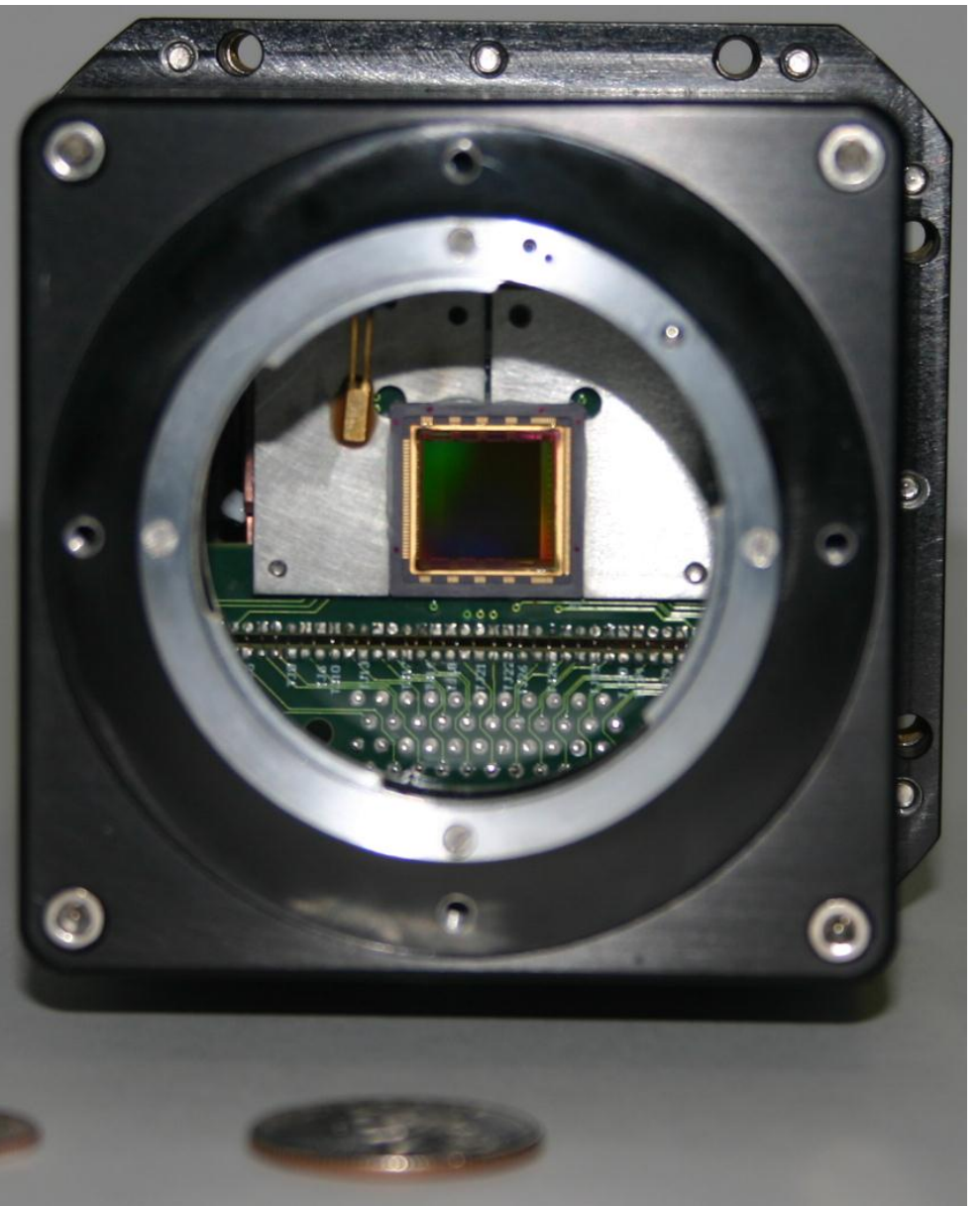




\section{Major components of the Model 1050 radiation tolerant dump-and-read camera}

- Imaging device is a CMOSIS@ CMV4000-25EMOPN CMOS image sensor

$-2 \mathrm{k} \times 2 \mathrm{k}$ active pixels on 5.5 micron pitch

- 8 transistor architecture with pinned photodiode

- Global shutter, global reset and correlated double-sampling capabilities

- Pinned photodiode and 5 micron Epitaxial layer (EPI) should aid in reducing image noise and increase survivability to radiation

- Control and readout done with Actel@ 3PE600L Field Programable Gate Array

- 600,000 gates

- Want to compare this device with their $\mathrm{RT}$ radiation hardened device since both are made on same production line

- Radiation tolerant RT ProASIC family with the ability to operate up to 15 to $25 \mathrm{krad}(\mathrm{Si})$

- Program stored in 3D Plus ${ }^{@}$ radiation tolerant memory good to 15 krad(Si)

- Part selection based on a search of radiation effect reports and databases 


\section{Test plan for evaluation of the Model 1050 camera}

- Top level

- Pre-irradiation exposure measurements (complete in 2013)

- Irradiation in the NIF target chamber at fluences of $3 \times 10^{7}$ to $6 \times 10^{9} \mathrm{n} / \mathrm{cm}^{2}$ during deutrium/tritium (DT) fusion shots (2014)

- Post-irradiation exposure measurements - repeat of pre-radiation measurements (2014)

- Comparison of pre- and post-irradiation measurements to quantify degradation of camera performance

- Pre-radiation exposure measurements

- Read noise, full well capacity, dynamic range and gain constant (electrons/Digital Number (DN))

- Measurements done with Gamma Scientific@ RS-5 Digital Light Source System with flat field illuminator at $460 \mathrm{~nm}$ and $530 \mathrm{~nm}$ wavelength

- Determine time to transition from charge dump to exposure (charge collection)

- Measure jitter and effectiveness of charge dump 


\section{Summary of baseline camera performance}

- Classical photon transfer method used to calculate gain constant

- A 50x50 pixel array in virtual overscan area of bias images used to determine bias offset and the read noise

- Since this is an active pixel device, there is no physical overscan area as in CCDs

- A 50x50 pixel array in center of imager used to determine average signal over a range of illumination intensities giving dynamic range

- Measurements made at two gain settings

\begin{tabular}{ccccc}
\hline $\begin{array}{c}\text { Cam. Gain } \\
\text { Setting }\end{array}$ & $\begin{array}{c}\text { Cam. Gain Constant } \\
\left(\mathrm{e}^{-} / \mathrm{DN}\right)\end{array}$ & $\begin{array}{c}\text { Read Noise } \\
\left(\mathrm{e}^{-}\right)\end{array}$ & Full Well (e-) & Dynamic Range \\
\hline $1.0 \mathrm{X}$ & 4.6 & 23 & 13800 & 600 \\
$1.6 \mathrm{X}$ & 2.6 & 21 & 9800 & 467 \\
\hline \hline
\end{tabular}

The 1.0X full well measurement is within $3 \%$ of manufacturer specification 


\section{Test setup for timing and sensor light response}

- Determined delay and jitter from trigger through dump time to start of exposure time

- Determined length of time camera responds to light after our set exposure time ends

- Timing between camera trigger, exposure start time, laser pulse and the sensor clock are recorded on an oscilloscope

- Relative timing between laser and camera trigger controlled by DG-535 delay generator

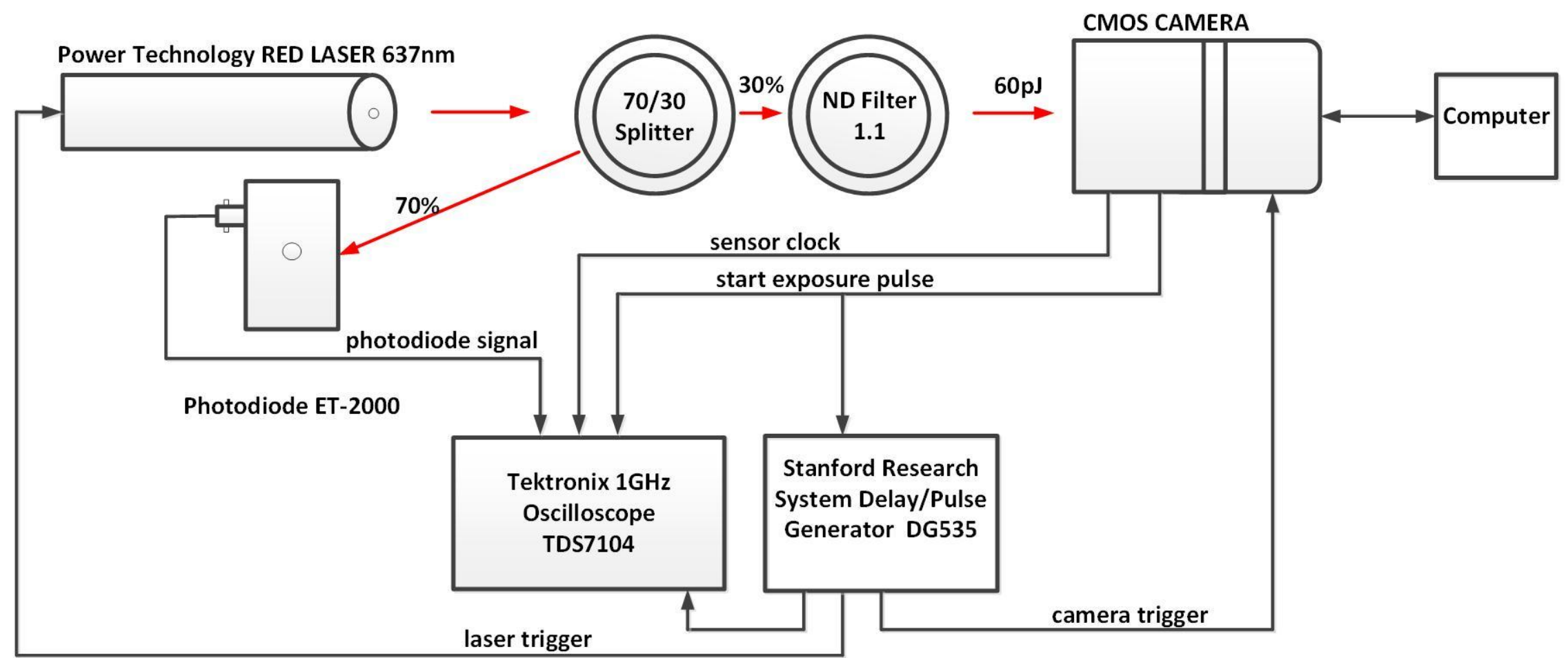




\section{Timing, jitter and start of exposure}

- To use the camera in a dump-and-read mode, the delay and jitter from trigger through dump time to start of exposure need to be determined

- Delay and jitter are function of the camera's two asynchronous clocks

- The sensor chip clock has a period of $120 \mathrm{~ns}(8.33 \mathrm{MHz})$

- The camera's state machine clock has a period of $50 \mathrm{~ns}$

- the dump period is adjustable from 100ns to $3.28 \mathrm{~ms}$ in $50 \mathrm{~ns}$ steps

- exposure period is adjustable in $1 \mathrm{~ms}$ steps from $1 \mathrm{~ms}$ to 65.5 seconds

- Time from trigger in to start of exposure varied from 1040ns to $1210 \mathrm{~ns}$

- This time includes the additional 7 sensor clock steps (840ns) before sensor fully responds to light

- The 170 ns variation is due two sources

- Uncertainty in the arrival time of camera trigger in to the 50ns clock edge

- Uncertainty of the camera start exposure line matching the falling edge of the 120ns sensor clock

- The sensor is still light sensitive 133us after end of exposure period 


\section{Example of timing and image showing first response to light at 7 clock cycles after the camera trigger}

- Scope trace showing the $60 \mathrm{pJ}$ laser pulse (FWHM 15ns) with respect to start of exposure and the sensor's 120 ns clock.

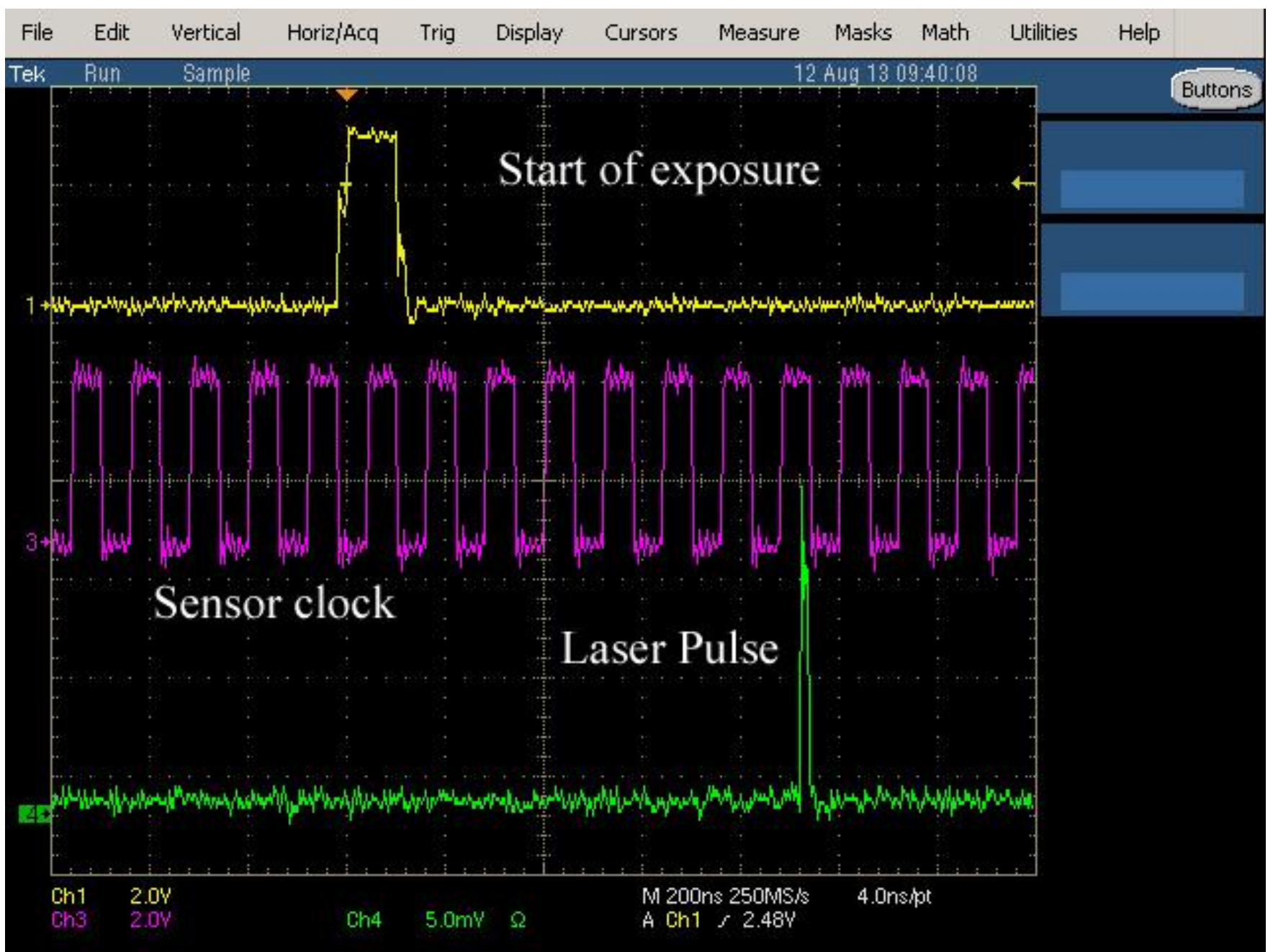




\section{Response of camera at start of exposure}

- Plot shows the response of the sensor chip and time after the start of exposure signal reaches the chip. Takes 7 clock cycles (840ns with the rise in approximately 1 clock cycle.

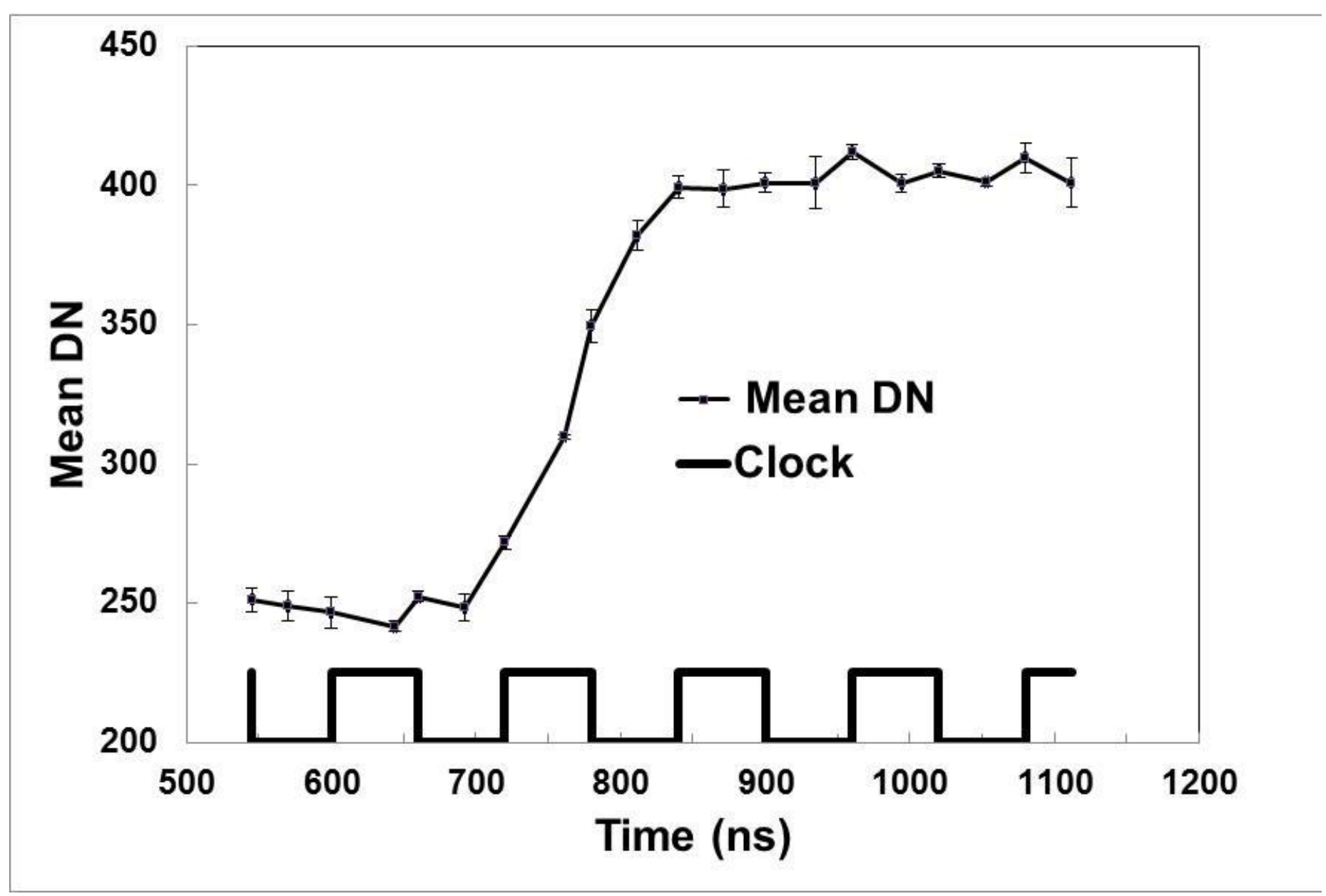




\section{Conclusion}

- Pre-radiation measurements show camera has the potential to replace current Spectral Instruments@ ${ }^{\circledR} 1000$ series cameras

- Dynamic range of 600 exceeds diagnostic requirements of $\mathbf{3 0 0}$

- The 5.5 micron pixel pitch does not match current pixel pitch of 9 microns

- Prefer 4kx4k imager with 8 to 12 micron pixel size

- The 170ns variation in time between trigger in and actual start of exposure is acceptable for current applications. If needed can reduce delay and jitter by changing sensor clock from $8.33 \mathrm{MHz}$ (120ns period) to $48 \mathrm{MHz}$ (20.8 ns)

- The operating software and mechanical interface allows seamless transition from 1000 series cameras in National Ignition Facility operations

- Future tests will evaluate the global dump timing and effectiveness in a radiation environment

- Acknowledgment to Spectral Instruments ${ }^{\circledR}$ for the development of the prototype dump and read camera 